\title{
The impact of biological and cultural racisms on attitudes towards immigrants and immigration public policies
}

\section{Alice Ramos, Cicero Roberto Pereira \& Jorge Vala}

To cite this article: Alice Ramos, Cicero Roberto Pereira \& Jorge Vala (2020) The impact of biological and cultural racisms on attitudes towards immigrants and immigration public policies, Journal of Ethnic and Migration Studies, 46:3, 574-592, DOI: 10.1080/1369183X.2018.1550153

To link to this article: https://doi.org/10.1080/1369183X.2018.1550153

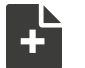

View supplementary material $\sqsubset$

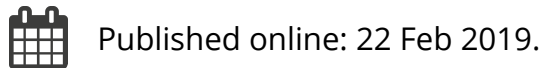

Submit your article to this journal

III Article views: 498

Q View related articles $\asymp$

View Crossmark data ־

en

Citing articles: 3 View citing articles $\widetilde{ }$ 


\title{
The impact of biological and cultural racisms on attitudes towards immigrants and immigration public policies
}

\author{
Alice Ramos $\mathbb{1}^{\mathrm{a}}$, Cicero Roberto Pereira $\mathbb{( D D}^{\mathrm{a}, \mathrm{b}}$ and Jorge Vala (D) $^{\mathrm{a}}$ \\ ${ }^{\mathrm{a}}$ Institute of Social Sciences, University of Lisbon, Lisboa, Portugal; ${ }^{\mathrm{b}}$ Federal University of Paraíba, Cidade \\ Universitária, João Pessoa, Brazil
}

\begin{abstract}
Based on ESS-7 data, this paper focuses on two attitudinal dimensions about public policies related to immigration: how many can come and who can come. In this context, the hypothesis concerning the bi-dimensionality of racism was supported and, as predicted, biological racism is more antinormative than cultural racism. Both biological and cultural racism predict opposition to immigration and adhesion to ethnicist criteria on the selection of immigrants. As hypothesised, the relationship between racism and opposition to immigration and adhesion to ethnicist criteria is mediated by threat perceptions. Specifically, symbolic and realistic threats mediate the effect of biological and cultural racism on opposition to immigration and on ethnicist criteria. The hypothesis that the mediation effects are moderated by the country's quality of democracy was supported, indicating that the mediation effects are stronger in countries with a higher quality of democracy. Results are discussed within the context of racism theories as a bi-dimensional concept and in the framework of the role of legitimation processes in social discrimination.
\end{abstract}

\section{KEYWORDS}

Racism; racial prejudice; immigration; threat perceptions; legitimation; discriminatory attitudes

\section{Introduction}

The horror of the Second World War, the progressive expansion of the Universal Declaration of Human Rights approved in 1948, the success of African liberation movements and of the struggle of Afro-Americans for civil rights, as well as other social movements across Europe in favour of democratic and more equalitarian societies are all important moments in the delegitimising of the idea of race. These social processes have promoted the rejection of social inequalities founded on race, and the gradual dissemination of the anti-racist norm. The effect of this norm resulted in a significant decline in negative stereotypical traits attributed to black people in the United States between the 1930s and the 1990s (Dovidio and Gaertner 1998). On the other hand, in their study on racial prejudice towards immigrants conducted in four European countries (France, The Netherlands, the United Kingdom and Germany), Pettigrew and Meertens (1995) showed that racial prejudice was manifested more through the absence of positive feelings about immigrants 
than through the expression of negative ones. Similar results were obtained in Portugal (Vala, Lopes, and Brito, 1999; Vala, Lopes, and Lima 2008), in Spain (Pérez 1996), and in other European countries, like Italy (Arcuri and Boca 1999; for a review see Zick, Pettigrew, and Wagner 2008). Overall, these studies have shown it is not normative ${ }^{1}$ to express openly negative attitudes towards members of groups who have historically been targets of racialization (e.g. Quillian 2006).

However, a line of research measuring automatic associations between words (e.g. positive vs negative) and targets of evaluation (e.g. whites vs blacks) showed that racial prejudice remains active at an implicit or unconscious level (Gaertner and McLaughlin 1983).

This line of research became prominent through the dissemination of studies carried out by Greenwald and collaborators (e.g. Greenwald, McGhee, and Schwartz 1998; Nosek, Greenwald, and Banaji 2005). Using the well-known Implicit Association Test (IAT), they demonstrated that white participants associated negative traits with black people faster than with white people. IAT and other measures using response latencies are genuine non-obstructive measures of attitudes that allow us to question whether racial prejudice is really decreasing (for a review, Dijksterhuis 2010; Fazio and Olson 2003).

Another research line, also using unobtrusive measures, has shown that white people invest more time in making an impression or a decision about a white target than about a black target. Such an intergroup time bias demonstrates that anti-black discrimination continues to be pervasive in everyday life (Vala et al. 2012). In sum, what studies using implicit prejudice or discrimination measures have shown is that racial prejudice is alive, albeit 'hidden' or expressed through less explicit ways.

This paper intends to go further in the analysis of racism and its consequences in contemporary European societies: we propose that racism is not only 'hidden' but has undergone transformations that allow its widespread and socially effective persistence. Our hypothesis is that racism, as a social representation of the insurmountable natural hierarchy of human groups, continues active and has evolved from a traditional biological basis to a cultural basis. The paper also proposes that both biological and cultural racism impact on opposition to immigration and discriminatory ethnicist anti-immigration policies. Moreover, according to the Model of Justified Discrimination (Pereira, Vala, and CostaLopes 2010), it is hypothesised that perceptions of symbolic and realistic threat function as legitimising factors of discrimination, mainly in social contexts where the anti-racism norm is more salient. The hypotheses tested in this paper are part of an overall model to explain opposition to immigration presented in the introduction of this special issue (Heath et al. 2020).

\section{Adaptive changes of racist beliefs: an evolving virus}

The decline of racial prejudice is, at least in part, an illusion that implicit measures of prejudice help to question (Gawronski et al. 2017), showing how the anti-racism norm is able to inhibit the open expression of prejudice when people are able to control their answers. This, however, is not so in everyday life situations, where people respond automatically or in conditions under which they cannot control their answers. Furthermore, regarding racism not as a mere negative attitude or discrimination towards devalued outgroups but as a social theory about the natural hierarchy of human groups, some changes 
have also occurred in response to the pressure of the anti-racist norm (e.g. Balibar 1991/ 2007). In this context, Sears and McConahay (1973) proposed, in the USA, the concepts of symbolic or modern black racism; and Pettigrew and Meertens (1995) showed the emergence of subtle prejudice about immigrants in four European Countries. Both studies showed that negative attitudes towards black people or immigrants are now mainly based on cultural instead of biological features.

Nonetheless, the measurement instruments used in those studies always have a specific target group that is evaluated (e.g. Black people, people coming from countries perceived as culturally different, Gypsies, Jews, etc.). Actually, traditional measures of racism or racial prejudice do not address general beliefs about the hierarchy and essentialisation of human groups' differences or about the idea that some groups, cultures or 'races' are inferior. Different from those traditional forms of inquiry, Pereira and Vala (2012) proposed a measure intending to evaluate the beliefs about the hierarchy of human groups based on biological factors (e.g. 'some races are more gifted than others'; 'the human species is divided into racial groups that are very different from each other') or based on cultural factors ('some cultures are superior to others', 'we need to protect our own culture from the influence of other cultures').

The authors also proposed that rather than seeing racism as a unitary phenomenon, it can be conceptualised as comprising two distinct dimensions: biological racism - when people organise their representation of humanity based on the idea of 'race', i.e. that human beings can be categorised and hierarchised into racial groups; and cultural racism (or ethnicism) - when people organise their representations of humanity based on the idea of 'ethnicity' i.e. that human beings can be categorised and hierarchised into ethnic groups (Pereira, Vala, and Costa-Lopes 2009). This distinction between cultural racism and biological racism deepens the differentialist racism proposed by Taguieff (1984) and the concept of 'new racism' or cultural racism proposed by Barker (1981) and discussed by Balibar (1991/2007). The possibility of a racism based on culture was already previewed by Lévi-Strauss in his seminal work about race and history (1952). Balibar speaks about a 'racism without races' (p. 84) in the context of the new relations of domination in European countries that emerged in the post-colonial era. Balibar describes this racism as having as its dominant theme not biological heredity but 'the insurmountability of cultural differences (...) where culture functions as nature' (p. 84). According to Balibar (1991/2007, p. 86), 'we see how the return of the biological theme is permitted and with it the elaboration of new variants of the biological 'myth' within the framework of a cultural racism'. In the humanities' domain, the contribution of Said (1994) constitutes a conceptual foresight of cultural racism. From this set of theoretical contributions, we derived two hypotheses: it is empirically possible to distinguish biological and cultural racism $(\mathrm{H} 1)$; biological racism is more anti-normative than cultural racism $(\mathrm{H} 2)$.

\section{Attitudes towards ethnicist criteria on the selection of immigrants}

This question implies several attitudinal dimensions, such as attitudes related to allowing people to come or not; defining how many can come or not; deciding how to integrate those who come; and establishing criteria for selecting those who can come or not. The first two problems have been extensively studied, from different perspectives (e.g. Davidov et al. 2008; Morales, Pilet, and Ruedin 2015; Ramos, Pereira, and Vala 2016; 
Green 2009). The perspective on modalities of integration of immigrants has also been deeply analysed (e.g. Bourhis et al. 1997; Guimond, Sablonnière, and Nugier 2014; Heath et al. 2013).

However, with few exceptions (e.g. Pehrson and Green 2010), the study of the characteristics immigrants must have (like skin colour, religion or language) in order to be welcomed in the hosting country has received less attention. For instance, President Trump has established new selection rules, based on religion, for immigrants entering the USA. We call those criteria ethnicist because they reflect the common sense idea that members of a given human group have a common ancestry based on cultural essences, as proposed, for instance by Huntington (1996). In this line, it has also been proposed that when people from the hosting countries and immigrants belonging to different cultures are put together, a clash of civilisations is probable or, at least, integration and constructive dialogue between the two cultures will be difficult (e.g. Huntington 1996, 2004; Lewis 2002).

Consequently, the fundamentals endorsing the ethnicist criteria for selecting immigrants are to protect the very nature of the culture of the majority, and its implicit superiority. As this reasoning involves the idea of deep and insurmountable differences between human groups, we propose the hypothesis that the higher the adhesion to biological or cultural racist beliefs, the higher the opposition to immigration $(\mathrm{H} 3 \mathrm{a})$ and the support for ethnicist criteria in the selection of immigrants (H3b). Indeed, we hypothesise that opposition to immigration and ethnicist criteria in the selection of immigrants are two distinct, although correlated, dimensions

Following the work developed by Pereira, Vala, and Leyens 2009 and Pereira, Vala, and Costa-Lopes 2010, according to which the path from racism to discrimination needs to be legitimised by socially accepted justifications, we propose that perceptions of threat (symbolic and realistic) act as legitimation factors in the relationship between biological and cultural racism, and opposition to immigration and support for ethnicist criteria of immigrant selection.

\section{Threat perceptions as legitimising factors of discrimination in the context of contemporary formal democratic societies}

Legitimation refers to the social and psychological processes by which attitudes and behaviours are justified and perceived as appropriate, conforming to social norms, and fair. Legitimation and legitimacy are fundamental factors in interpersonal, intergroup, social and institutional functioning (for a review see Tyler 2006; Costa-Lopes et al. 2013; Jost and Major 2001; White and Crandall 2017). Legitimising ideologies of the status quo like meritocracy (e.g. McCoy and Major 2007), social dominance orientation (Guimond et al. 2003; Sidanius and Pratto 1999) or system justification (Jost and Hunyady 2005) facilitate the expression of prejudice. Moreover, Belief in a Just World, another ideology of legitimation, is related to less perceived discrimination (Hafer and Bègue 2005). Consequently, there is theoretical and empirical evidence for the need of legitimising prejudice and discrimination in contemporary societies.

The psychological mechanism involved in legitimising processes of racial prejudice have been specifically analysed by the Theory of Aversive Racism (Gaertner and Dovidio 1986) and the Justification - Suppression Model (Crandall and Eshleman 2003). Both 
theories propose that normative justifications allow individuals to express prejudice without feeling or perceiving auto or hetero disapproval and, consequently, protect their self-esteem.

The Justified Discrimination Model (JDM) (Pereira, Vala, and Leyens 2009; Pereira, Vala, and Costa-Lopes 2010) has also examined the hypothesis that discrimination should be legitimised specifically in contexts where the egalitarian norm is salient (Pereira, Vala, and Leyens 2009). Beyond the model proposed by Stephan and Stephan (2000), the JDM proposes that realistic and symbolic threat perceptions are legitimating factors that mediate the relationship between racial prejudice and discriminatory attitudes (Pereira, Vala, and Costa-Lopes 2010). Specifically, in this paper, we propose that realistic and symbolic threat perceptions mediate the relationship between racism and opposition to immigration ( $\mathrm{H} 4 \mathrm{a})$ and support for ethnicist criteria $(\mathrm{H} 4 \mathrm{~b})$.

A further hypothesis (H5) will be tested in this research: we propose that the mediation role of threat perceptions will be moderated by the quality of democracy measured at a contextual-structural level. As Pereira, Vala, and Leyens (2009) demonstrated, in an experimental study, the referred mediation only occurs in a context where the egalitarian democratic principles were salient, because it is in this kind of context that the need of legitimation is more pronounced and, consequently, discrimination should be justified. Extending this rational to the contextual level, we anticipate that the relationship between racism and negative attitudes to immigrants will be strongly mediated by threat perception in countries that rank higher on the Quality of Democracy Index (QDI). This hypothesis is based on the assumption that in higher QDI societies egalitarianism is more salient, i.e. where the principle that all citizens deserve to be treated with the same consideration and be subject to the same degree of inclusion is highly predominant (Bühlmann et al. 2012). Consequently, the need for justifying discrimination will be stronger in countries with higher QDI scores than in countries with lower QDI scores.

\section{Method}

\section{Samples}

The data analysed corresponds to ESS Round 7 representative samples of all persons aged 15 and over (no upper age limit) resident within private households in each of the 20 selected countries regardless of their nationality, citizenship or language; adding up to a total of 39,860 participants. Respondents who identified themselves as immigrants or had not been born in the country where the data was collected were excluded from the analysis. This procedure reduced the total sample to 30,355 respondents.

\section{Measures}

\section{Racism}

The ESS7 has three items aimed at measuring racism, two being for biological racism and one for cultural racism. Biological racism was measured by the following items: 'Do you think some races or ethnic groups are born less intelligent than others?'; 'Do you think some races or ethnic groups are born harder working than others?'. The participants 


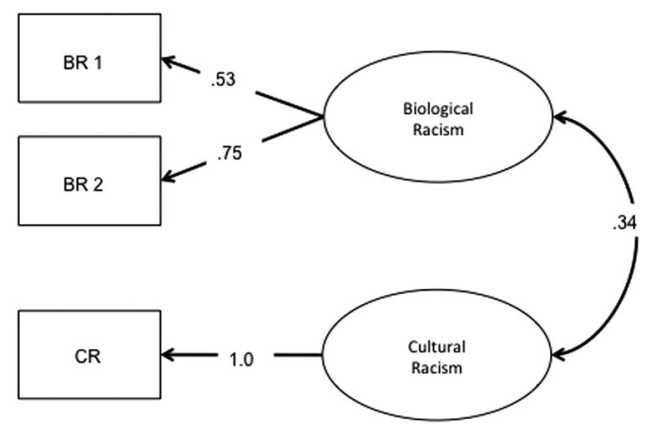

Figure 1. Biological and Cultural Racism (CFA).

Note: All coefficients are significant at $p<.001$.

indicated whether they agreed or not with each question (1-yes; 0 -no). Cultural racism is found through the answers to the question 'Thinking about the world today, would you say that some cultures are much better than others or that all cultures are equal?' Participants' responses were coded with 1 (some cultures much better) or 0 (all cultures equal). Two latent variables (Biological Racism and Cultural Racism) were then specified using the three items (see Figure 1). For a discussion on this procedure using big samples, see Muthén and Kaplan (1985) and Fan, Thompson and Wang, L. (1999).

\section{Threat perceptions}

The ESS7 has five items measuring threat perceptions. Three of them tap realistic threat perceptions: 'Would you say it is generally bad or good for [country's] economy that people come to live here from other countries?' (0-Bad for the economy to 10-Good for the economy); 'Would you say that people who come to live here generally take jobs away from workers in [country], or generally help to create new jobs?'; (0- Take jobs away to 10-Create new jobs); 'Are [country]'s crime problems made worse or better by people coming to live here from other countries?' ( $0=$ Crime problems made worse to $10=$ Crime problems made better). The rating of these three items was reversed and used to specify a latent variable representing realistic threat perceptions. Complementing this, two indicators measure the perception of symbolic threat: 'Would you say that [country]'s cultural life is generally undermined or enriched by people coming to live here from other countries?' (0-cultural life enriched to 10-cultural life undermined); 'Do you think the religious beliefs and practices in [country] are generally undermined or enriched by people coming to live here from other countries?' (0 -Religious beliefs and practices enriched to 10-Religious beliefs and practices undermined. These two items were used to specify a latent variable of symbolic threat perceptions.

A Confirmatory Factor Analysis was then specified comprising two correlated latent variables representing realistic and symbolic threats. Results showed a very good fit to the data: $\chi 2(4, N=30561)=831.34, p<.001 ; \mathrm{CFI}=.98$; TLI $=.95$; RMSEA $=.08$; $\mathrm{BIC}=$ 613442.54. An alternative model, representing a uni-factorial solution was also specified. However, the fit to the data was not as good as the bi-factorial solution: $\chi^{2}(5$, $N=30561)=1788.61, p<.001 ; \mathrm{CFI}=.96 ; \mathrm{TLI}=.91 ; \mathrm{RMSEA}=.10 ; \mathrm{BIC}=614389.48$. In fact, the bi-factorial solution shows a better fit than the uni-factorial one, $\chi^{2}(1, N=$ 
30561 $)=907.27, p<.001$, indicating that the five items better represent two distinct dimensions of threat perceptions than a general dimension.

\section{Ethnicist criteria of immigrants' admission}

The items that operationalise ethnicist policies are the following:

"Please tell me how important you think each of these things should be in deciding whether someone born, brought up and living outside [country] should be able to come and live here: be able to speak the country's official language; be white; come from a Christian background" (0-Extremely unimportant to 10-Extremely important).

These three items were used to specify the latent variable 'ethnicist admission policies' (Cronbach alphas higher than .60 in 14 countries and ranging from .52 to .59 in 6 countries).

\section{Opposition to immigration}

From a battery of questions asking about the country's availability to receive people originally from different locations and with different backgrounds, we selected the two that best describe the group of immigrants Europe has been hosting over recent decades: "Using this card, please tell me to what extent you think [country] should allow: a) people from a different race/ethnic group; b) people from the poorer countries outside Europe to come and live here (1-Allow many to 4-Allow none). One latent variable was specified using these two items to operationalise opposition to immigration (Cronbach alphas ranging from .79 to .92 in the 20 countries).

In our proposal, 'opposition to immigration' and 'ethnicist criteria of immigrant selection' are two different dimensions of discrimination towards immigrants. In order to support this hypothesis, we compared two measurement models using Confirmatory Factor Analysis. In the first one, we specified the set of five items as measuring two correlated latent variables (Opposition to Immigration; and Ethnicist Criteria). In the second model, we specified the items to loading on a single latent variable, representing a general discriminating orientation. The results showed that the proposed two factorial solution fits the data very well $\left(\chi^{2}(4, N=30207)=669.04, p<.001 ;\right.$ CFI $=.96$; TLI $=.90$; RMSEA $=.07 ; \mathrm{BIC}=553061.81)$, while the single factor solution has a poor fit $\left(\chi^{2}(5, N\right.$ $=30207)=4004.91, p<.001 ; \quad \mathrm{CFI}=.77 ; \quad \mathrm{TLI}=.54 ; \quad \mathrm{RMSEA}=.16 ; \quad \mathrm{BIC}=561913.36)$. Importantly, the bi-factorial solution fits the data significantly better than the uni-factorial one, $\Delta \chi^{2}(1, N=30207)=3335.87, p<.001$, which reinforces our proposal that the five items measure different concepts.

\section{Quality of democracy}

The quality of democracy of each country was assessed using the database from the Democracy Barometer (www.democracybarometer.org/index.html, 2014). This measure is based on the premise that in a democratic system, there is a good balance between the normative, interdependent values of freedom and equality and that this requires institutional regulation (Bühlmann et al. 2012). The general quality of democracy score was used because it encompasses the three main features of democratic regimes, as defined in the Democracy Barometer: freedom, control and equality. The scores can vary from 0 (representing countries with the worst democratic practices) to 100 (representing 
countries with the best democratic practices). In the present study, democracy quality scores (observed in 2014) vary between 46 and $76(1-100$ scale) $(\mathrm{M}=59.68, \mathrm{SD}=7.14)$.

\section{Results}

The main hypotheses presented were tested using structural equation models (SEM) and multilevel analysis, whose parameters were estimated in Mplus version 6.0 (Muthén and Muthén 1998-2010), according to the method of maximum likelihood. For each SEM analysis, parameters were initially estimated for the whole sample. The procedure was then repeated for each country. When estimating mediation parameters, bootstrap procedures with 1000 re-samplings were used and reported the $90 \%$ bias corrected confidence intervals. In each model, the factorial loading of one of the indicators of each latent variable was constrained at 1.00. Concerning cultural racism that has only one indicator, we followed the Kenny, Kashy, and Bolger (1998) recommendation constraining its error variance to 0.00 , in order to guarantee the statistical identification of the model. All models were estimated with random intercept and slopes.

Results are organised in three sections: a) the factor structure and descriptive analysis of biological and cultural racisms, performed using Structural Equation Models; b) the mediation effects of threat perceptions on opposition to immigration and on the support for ethnicist criteria; and, c) the moderation effect of quality of democracy, both performed using multilevel regression models.

Data was weighted according to the statistical procedures used. Specifically, in the analyses involving all the countries, or between-country comparisons, a combination of population weight (pweight) and design weight (dweight) was used. Post-stratification weight was used in the descriptive analysis of biological and cultural racism. Design weight was used in other within countries analysis.

\section{Racism: a bi-dimensional concept}

According to the first hypothesis, racism is not a single concept, but encompasses two correlated dimensions: biological racism and cultural racism. Findings show that, overall, the correlation between the two items of biological racism is moderately strong $\left(r_{\mathrm{br} 1{ }^{*} \mathrm{br} 2}=.39\right.$, $p<.001)$. This correlation is stronger than the correlation between each biological racism item and the cultural racism one $\left(r_{\mathrm{br} 1^{*} \mathrm{cr}}=.24, p<.001\right.$, and $\left.r_{\mathrm{br} 2^{*} \mathrm{cr}}=.23, p<.001\right)$. This pattern of association occurred in each of the 20 European countries considered. To analyse the factorial structure of racism items, two Confirmatory Factor Analysis (CFA) were estimated, one specifying biological and cultural racisms as two latent variables (Figure 1$)^{2}$, and another one specifying a uni-factorial solution.

Results indicate a moderated correlation between the factors $(r=.32, p<.001)$ on the bi-factorial solution with the followings fit indices: $\chi^{2}(1, N=30207)=191.39, p<.001$; $\mathrm{CFI}=.97$; TLI $=.91 ; \mathrm{RMSEA}=.07 ; \mathrm{BIC}=101407.18$. Results of the uni-factorial solution show an unsatisfactory goodness-of-fit: $\chi^{2}(2, N=30207)=5274.81, p<.001 ; \mathrm{CFI}=.13$; $\mathrm{RMSEA}=.30 ; \mathrm{BIC}=106844.15$. Moreover, the bi-factorial solution shows a better fit than the uni-factorial one, $\Delta \chi^{2}(1, N=30207)=5083.42, p<.001$. This result pattern was observed in each of the 20 countries and confirms our first hypothesis $\left(\mathrm{H}_{1}\right)$, according to which racism is not a single but a bi-dimensional concept. 
Table 1. Belief in biological and cultural racism (percentages, confidence intervals in brackets).

\begin{tabular}{lllr}
\hline & \multicolumn{1}{c}{ Biological racism } & Cultural racism & Difference biological/cultural \\
\hline Austria & $28.6(26.7$ to 30.5$)$ & $33.4(30.7$ to 36.1$)$ & -4.8 \\
Belgium & $31.4(29.4$ to 33.3$)$ & $39.7(37.0$ to 42.4$)$ & -8.3 \\
Switzerland & $35.8(33.5$ to 38.1$)$ & $37.8(34.4$ to 41.1$)$ & -2 \\
Czech Republic & $44.7(42.7$ to 46.6$)$ & $58.6(56.3$ to 60.9$)$ & -13.9 \\
Germany & $23.5(22.2$ to 24.7$)$ & $40.3(38.2$ to 42.3$)$ & -16.8 \\
Denmark & $28.0(26.2$ to 29.9$)$ & $62.1(54.4$ to 64.8$)$ & 8.1 \\
Estonia & $47.9(45.5$ to 50.4$)$ & $39.8(36.9$ to 42.7$)$ & -7.5 \\
Finland & $33.6(32.1$ to 35.2$)$ & $41.1(38.9$ to 43.4$)$ & 6.1 \\
France & $34.1(32.3$ to 35.9$)$ & $28.0(25.6$ to 30.4$)$ & -18.6 \\
Ireland & $30.5(28.8$ to 32.2$)$ & $49.1(46.8$ to 51.4$)$ & -34.8 \\
The Netherlands & $10.1(8.9$ to 11.3$)$ & $44.9(42.4$ to 47.5$)$ & -53.5 \\
Norway & $12.6(11.3$ to 13.9$)$ & $66.1(63.4$ to 68.8$)$ & -19.4 \\
Poland & $20.5(18.7$ to 22.2$)$ & $39.9(37.3$ to 42.6$)$ & -34.7 \\
Sweden & $8.5(7.4$ to 9.7$)$ & $43.2(40.5$ to 45.9$)$ & -7.6 \\
Slovenia & $31.6(28.9$ to 34.3$)$ & $39.2(35.9$ to 42.4$)$ & -18.2 \\
Spain & $25.5(23.8$ to 27.2$)$ & $43.7(41.2$ to 46.2$)$ & -2.2 \\
Hungary & $33.5(31.4$ to 35.6$)$ & $28.3(25.9$ to 30.6$)$ & -1.2 \\
Latvia & $28.1(26.2$ to 30.0$)$ & $33.4(31.2$ to 35.6$)$ & -26.6 \\
Portugal & $52.9(50.4$ to 55.3$)$ & $54.1(51.1$ to 57.0$)$ & -14.8 \\
Great Britain & $31.2(29.4$ to 33.04$)$ & $57.8(55.4$ to 60.2$)$ & \\
Mean & $29.2(28.8$ to 29.6$)$ & $44.0(43.5$ to 44.6$)$ & \\
\hline
\end{tabular}

Note: Differences between countries are reliable for both biological (Intraclass Correlation $=.10, p<.001$ ) and cultural racism (Intraclass Correlation $=.05, p<.001$ ).

The second hypothesis states that biological racism is more anti-normative than cultural racism. According to our findings, it is clear that people are more willing to admit that some cultures are much better than others than to admit that some groups are born more intelligent and more fitted to work than others (Table 1).

There are countries where $30 \%$ or more of the respondents believe in the natural superiority of some human groups (Belgium, Switzerland, Finland, Ireland, Slovenia, Great Britain, Portugal, Estonia, Czech Republic, France and Hungary), but there are also countries with percentages below 15\% (Sweden, The Netherlands, Norway). However, in the latter group we find a significant amount of people that express cultural racism. A different pattern, corresponding to high levels of agreement on biological and cultural racism, can also be found (e.g. Portugal, Czech Republic). Overall, these findings support our second hypothesis, that biological racism is more anti-normative than cultural racism. In fact, in all countries cultural racism is more expressed than biological racism, apart from three (Estonia, France and Hungary).

\section{Racism: a predictor of opposition to immigration and ethnicist criteria}

In order to test the remaining hypothesis, a set of multilevel regression analyses was estimated for each dependent variable (Table 2). Step one analyses the impact of biological and cultural racism (measured at an individual level of analysis), quality of democracy (measured at country level) and interaction terms of each type of racism and quality of democracy on the dependent variables. Step two tests the impact of racism on threat perceptions. Step three provides the final results of the mediation role of threat perceptions, testing also the moderation effect of the aggregate variable quality of democracy. All estimated parameters were controlled for individual subjective income, years of education, gender, age and left-right political orientation; all predictors were grand-mean centred. 
Table 2. Estimated parameters of moderated-mediation models for opposition to immigration and for admission policies.

\begin{tabular}{|c|c|c|c|c|c|c|}
\hline & \multicolumn{2}{|c|}{ Step 1} & \multicolumn{2}{|c|}{ Step 2} & \multicolumn{2}{|c|}{ Step 3} \\
\hline & $\begin{array}{l}\text { Opposit. } \\
\text { Immig. }\end{array}$ & $\begin{array}{l}\text { Ethnicist } \\
\text { criteria }\end{array}$ & $\begin{array}{l}\text { Realistic } \\
\text { Theat }\end{array}$ & $\begin{array}{l}\text { Symbolic } \\
\text { Threat }\end{array}$ & $\begin{array}{l}\text { Opposit. } \\
\text { Immig. }\end{array}$ & $\begin{array}{l}\text { Ethnicist } \\
\text { criteria }\end{array}$ \\
\hline Intercept & $2.48^{* * *}$ & $4.09^{* * *}$ & $5.51^{* * *}$ & $4.72^{* * *}$ & $2.47^{* * *}$ & $4.10^{* * *}$ \\
\hline \multicolumn{7}{|l|}{ Individual Level } \\
\hline Subjective Income & $-.09^{* * *}$ & -.04 & $-.32^{* * *}$ & $-.24^{* * *}$ & $-.02^{* *}$ & .04 \\
\hline Education & $-.04^{* * *}$ & $-.09 * * *$ & $-.08^{* * *}$ & $-.10^{* * *}$ & $-.01^{* * *}$ & $-.06^{* * *}$ \\
\hline Gender & -.01 & -.05 & $.10^{*}$ & -.07 & $-.03^{* *}$ & -.03 \\
\hline Age & $.01^{* * *}$ & $.02^{* * *}$ & .00 & $.01 *$ & $.01^{* * *}$ & $.02^{* * *}$ \\
\hline Left-Right & $.05^{* * *}$ & $.14^{* * *}$ & $.05^{* *}$ & $.10^{* * *}$ & $.03^{* * *}$ & $.12^{* * *}$ \\
\hline Biological Racism (BR) & $.31^{* * *}$ & $.85^{* * *}$ & $.61^{* * *}$ & $.64^{* * *}$ & $.15^{* * *}$ & $.65^{* * *}$ \\
\hline Cultural Racism (CR) & $.15^{* * *}$ & $.26^{* * *}$ & $.36^{* * *}$ & $.47^{* * *}$ & $.04^{* * *}$ & $.12^{* * *}$ \\
\hline Realistic Threat (RT) & & & & & $.16^{* * *}$ & $.10^{* * *}$ \\
\hline Symbolic Threat (ST) & & & & & $.10^{* * *}$ & $.24^{* * * *}$ \\
\hline \multicolumn{7}{|l|}{ Country Level } \\
\hline $\begin{array}{l}\text { Quality of Democracy } \\
\text { (QD) }\end{array}$ & $-.02^{*}$ & $-.09 * * *$ & -.01 & $-.03^{*}$ & $-.01^{*}$ & $-.08^{* * *}$ \\
\hline $\mathrm{BR}^{*} \mathrm{QD}$ & .01 & $.02^{*}$ & .01 & .01 & .00 & .01 \\
\hline$C R^{*} Q D$ & .00 & .00 & $.01^{*}$ & $.01^{*}$ & .00 & .00 \\
\hline $\mathrm{RT}^{*} \mathrm{QD}$ & & & & & .00 & .00 \\
\hline$S T^{*} Q D$ & & & & & .00 & $.01^{*}$ \\
\hline \multicolumn{7}{|l|}{ Variance Components } \\
\hline Individual Level, $r_{0}$ & $.51^{* * *}$ & $3.50 * * *$ & $2.43^{* * *}$ & $3.21^{* * *}$ & $.37^{* * *}$ & $3.22^{* * *}$ \\
\hline Country Level, $\mathrm{u}_{0}$ & $.05^{* * *}$ & $.47^{* *}$ & $.16^{* * *}$ & $.24^{* * *}$ & $.04^{* *}$ & $.41^{* * *}$ \\
\hline $\mathrm{U}_{\text {slope_BR }}$ & $.007^{*}$ & $.040 \dagger$ & .017 & $.059^{*}$ & $.004 \dagger$ & .040 \\
\hline$U_{\text {slope_CR }}$ & $.002 \dagger$ & .005 & $.014 \dagger$ & $.027^{*}$ & .001 & .011 \\
\hline $\mathrm{U}_{\text {slope_RT }}$ & & & & & $.001^{*}$ & .001 \\
\hline Uslope_ST $_{\text {ST }}$ & & & & & $.001 \dagger$ & $.002^{*}$ \\
\hline ICC & .10 & .17 & .06 & .07 & .07 & .15 \\
\hline
\end{tabular}

Note: Level 1, $N=30636$; Level 2, $N=20$; the estimated parameters are unstandardised coefficients; $\dagger<.10 ;{ }^{*} p<.05$; ${ }^{* *} p<.01 ;{ }^{* * *} p<.001$.

The results obtained in the first model (Table 2, Step 1) show that racism predicts both dependent variables, meaning that the higher the belief in biological and cultural racism, the higher the opposition to immigration and the support for ethnicist criteria on the selection of immigrants. These findings confirm our hypothesis ( $\mathrm{H} 3 \mathrm{a}$ and $\mathrm{H} 3 \mathrm{~b}$ ) and also show that biological racism has a stronger impact on both opposition to immigration $(\Delta \mathrm{b}=15, \mathrm{SE}$ $=.03, p<.001)$ and ethnicist criteria $(\Delta \mathrm{b}=56, \mathrm{SE}=.05, p<.001)$ than cultural racism.

\section{The mediation role of threat perceptions}

Our hypotheses propose that the relationship between racism and discriminatory attitudes is mediated by threat perceptions. To test this model, it is necessary to analyse the impact of racism on threat perceptions, and the relation of these threats with each dependent variable (opposition to immigration and ethnicist criteria).

According to the results obtained in Step 2 (Table 2) of the multilevel analysis, it is confirmed that biological and cultural racism predict realistic and symbolic threat perceptions. Again, biological racism has a stronger effect than cultural racism. These results allow us to proceed with the mediation analysis.

The impact of biological and cultural racism on opposition to immigration and support for ethnicist criteria decrease when threat perceptions are included in the model (Step 3). These findings confirm our hypothesis ( $\mathrm{H} 4 \mathrm{a}$ and $\mathrm{H} 4 \mathrm{~b})$. It is also clear that the decrease is 
more expressive in the case of biological racism, suggesting that this dimension of racism needs further justification via threat perceptions than the cultural one.

These results indicate that symbolic threat perception mediates the effect of biological racism on opposition to immigration (indirect effect $=.08,90 \% \mathrm{CI}=.07$ to .09 ) and ethnicist admission policies (indirect effect $=.18,90 \% \mathrm{CI}=.16$ to .19 ). Similarly, realistic threat also mediated the effect of biological racism on opposition to immigration (indirect effect $=.11,90 \% \mathrm{CI}=.10$ to .12 ) and ethnicist admission policies (indirect effect $=.06,90 \% \mathrm{CI}$ $=.05$ to .07$)$.

Both realistic and symbolic threat perceptions mediate the relationship between cultural racism and opposition to immigration, respectively: indirect effect $=.07,90 \% \mathrm{CI}$ $=.06$ to .08 ; indirect effect $=.06,90 \% \mathrm{CI}=.05$ to .07 . Concerning ethnicist criteria, the effect of cultural racism is also mediated by realistic (indirect effect $=.04,90 \% \mathrm{CI}=.04$ to .05 ) and symbolic threat (indirect effect $=.14,90 \% \mathrm{CI}=.12$ to .15 ).

\section{Goodness-of-fit of the proposed model}

In order to proceed with the testing of our model, it is important to demonstrate its configuration validity i.e. that the pattern of relationships that we propose between racism, threat perceptions and discriminatory attitudes is better than alternative ones. This was made running a set of SEM analyses. The analysis of the goodness-of-fit indices for the proposed model show very good fit to the data: $\chi^{2}(51, N=30620)=$ $3621.94, p<.001, \mathrm{CFI}=.97, \mathrm{TLI}=.96, \mathrm{RMSEA}=.05, \mathrm{BIC}=1255643.82$. The fit of the hypothesised model was compared to the fit of two alternative models (AM1 and AM2). In AM1, symbolic and realistic threat perceptions are specified as two correlated latent variables predicting both biological and cultural racisms that, in turn, predict opposition to immigration and support of ethnicist criteria. In AM2, the dependent variable is racism and opposition to immigration and support of ethnicist criteria are specified as antecedents of both symbolic and realistic threat perceptions.

The comparison between the models shows that neither AM1 $\left(\chi^{2}(52, N=30620)=\right.$ 4614.62, $p<.001, \mathrm{CFI}=.96, \mathrm{TLI}=.94, \mathrm{RMSEA}=.05, \mathrm{BIC}=1256626.19)$ nor $\mathrm{AM} 2$ $\left(\chi^{2}(53, N=30620)=6671.21, \quad p<.001, \quad \mathrm{CFI}=.95, \quad \mathrm{TLI}=.92, \quad \mathrm{RMSEA}=.06, \quad \mathrm{BIC}=\right.$ 1258672.43) fit the data better than the proposed model. Actually, the proposed model fits better the data than AM1 $\left(\Delta \chi^{2}(1, N=33038)=992.68, p<.001\right)$, and AM2 $\left(\Delta \chi^{2}(2\right.$, $N=33038)=3049.27, p<.001)$. These comparisons were also performed within countries (see Annex 1-Online Materials). Results indicate that the proposed model fits better than both alternative models in every country, except in Norway where there are no significant differences between models. On the whole, these results demonstrate that it is empirically more consistent to consider threat perceptions as a consequence of racism or discriminating attitudes, rather than their predictors.

\section{The impact of the context: moderated mediation by quality of democracy}

According to the last hypothesis (H5), the more democracy is institutionalised, the more the dissemination of anti-racism norms is active and evaluations of minority groups based on racial attributes are strongly discouraged. This leads to the need of legitimising discriminatory attitudes for non-racial reasons, such as threat-based justifications. If this 
phenomenon occurs, the mediating role of threat perceptions is more evident in that the quality of democracy increases. The moderated-mediation can occur either on the effect of racism on threat perception, or on the effect of threat perceptions on the dependent variables (opposition to immigration and ethnicist criteria).

The moderated-mediation hypothesis was tested with a set of multilevel regression models (Table 2). The first stage of our reasoning consists of analysing the impact of Quality of Democracy on opposition to immigration and the support for ethnicist criteria. Results show that the higher the quality of democracy, the lower the discriminatory orientation. Importantly, the cross-level interaction between biological racism and quality of democracy is significant. Breaking down this interaction indicated that biological racism predicts the support for ethnicist criteria more strongly in countries that score higher on quality of democracy $(b=1.02, p<.001)$ than in countries that score lower $(\mathrm{b}=.69, p<.001)$ (Figure 2(b)).

In Step 2, the quality of democracy also has a negative effect on symbolic threat. Moreover, cross-level interactions between cultural racism and quality of democracy indicate that the effects of cultural racism on realistic and symbolic threats are stronger in countries with a higher quality of democracy. The decomposition of these interactions reveals that cultural racism predicts realistic and symbolic threats more strongly in countries that score higher on quality of democracy ( $+1 \mathrm{SD}$ from the mean: $\mathrm{b}=.44$; $\mathrm{SE}=.04, p<001$ and $\mathrm{b}=.58$; $\mathrm{SE}=.04, p<001$, respectively) than in countries that score lower $(-1 \mathrm{SD}$ from the mean: $\mathrm{b}=.27 ; \mathrm{SE}=.06, p<001$ and $\mathrm{b}=.36 ; \mathrm{SE}=.08, p<001$, respectively). These findings indicate that the mediating role of threat perceptions on the relationship between cultural racism and both opposition to immigration (Figure 2(a)) and support for ethnicist criteria (Figure 2(b)) is higher in countries with higher levels of democracy.

Moreover, Step 3 shows that the cross-level interaction between symbolic threat and ethnicist criteria is significant. The decomposition of this interaction indicates that the effect of symbolic threat is stronger in countries that score higher on quality of democracy $(\mathrm{b}=.26 ; \mathrm{SE}=.01, p<001)$ than in countries that score lower $(\mathrm{b}=.22 ; \mathrm{SE}=.02, p<001)$. This interaction indicates that the mediating role played by symbolic threat in the relationship between both racisms and ethnicist criteria is stronger in countries with a higher quality of democracy (Figure 2(b)).

\section{Discussion and conclusions}

This study offers new theoretical and empirical contributions to understanding the dimensions of racism, the impacts of racism on public policies related to immigration, and the role played by threat perception on the legitimation of individuals' support for discriminating attitudes towards immigrants in democratic societies. It was shown that both biological and cultural racisms impact on the opposition to immigration and on the support to ethnicist criteria on the selection of immigrants (to be white, Christian and able to speak the hosting country's language).

\section{Racism as a multidimensional belief}

Results showed that racism is better understood today considering its complex roots in the attribution of different biological and cultural essences to human groups resulting 

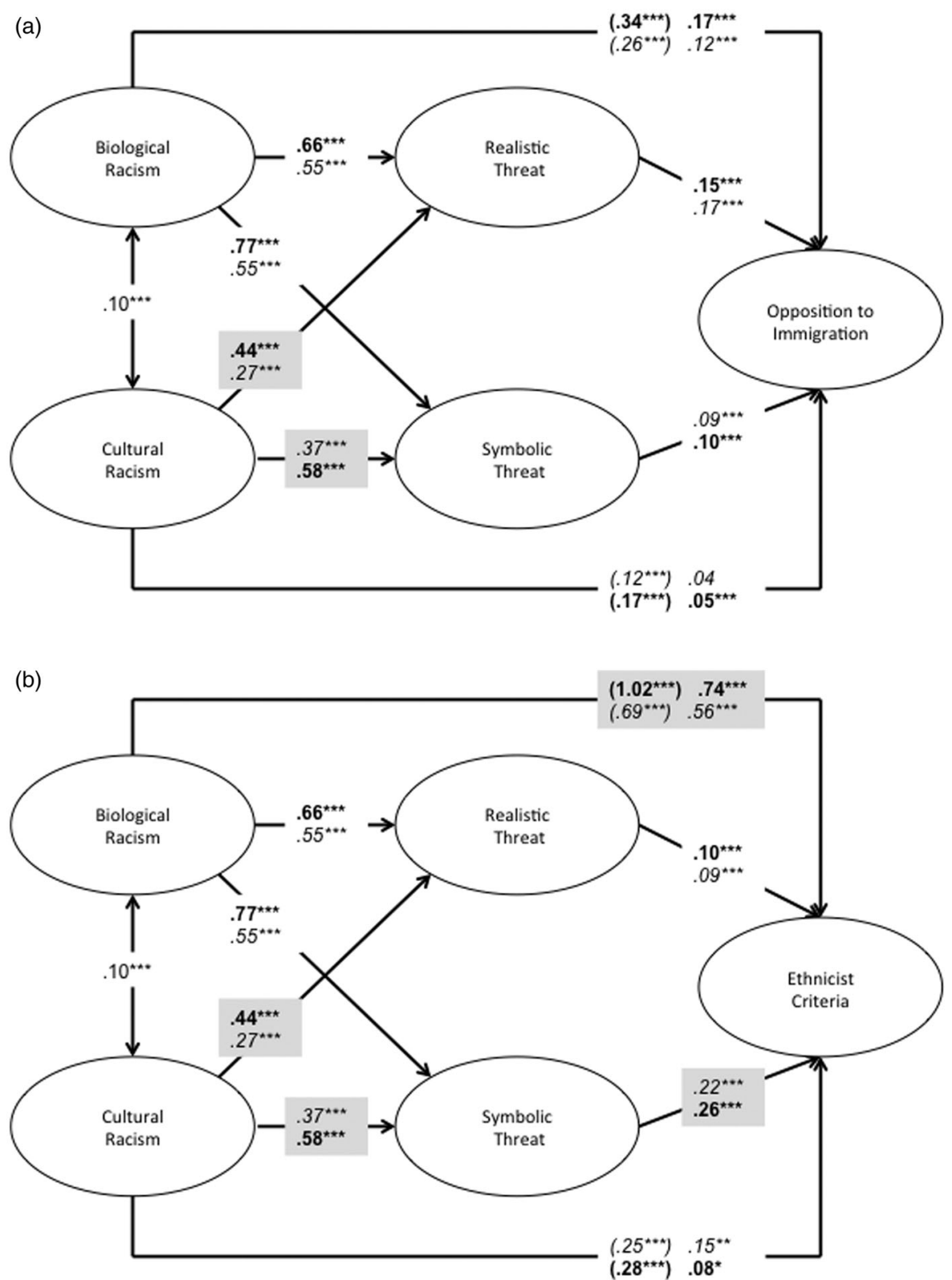

Figure 2. Racisms and opposition to immigration (Figure 2a) and ethnicist criteria (Figure 2b), mediated by threat perceptions and moderated by the quality of democracy (Unstandardised parameters).

Notes: ${ }^{*} p<.05 ;{ }^{* *} p<.01 ;{ }^{* * *} p<.001$. Coefficients in bold refer to countries with high scores on the quality of democracy index; the shaded boxes refer to statistically significant differences).

in the superiority of some groups relatively to others and even in the attribution of infra-humanity or radical alterity to some groups. The items designed to measure racism were the object of two CFAs, one specifying two latent variables and the other a uni-factorial solution. Results sustained our hypothesis about the bi- 
dimensionality of racism, one based on genetic essences and another on cultural essences. These results are important because, as far as we know, they constitute the first empirical demonstration of the complexity of racist beliefs through representative samples across Europe. Moreover, descriptive statistics suggest that biological racism is not supported by the majority of people, albeit $29 \%$ of the 30000 people inquired did manifest acquiescence.

As predicted, the cultural based inferiority of some social groups is less anti-normative than the biological one. These results can contribute to today's conceptual debate about the nature of racism in European societies, the social inequalities it promotes and the psychological and political processes it involves (e.g. Balibar 1991/2007; Leach 2005; Ford 2008; Vala 2013; Walker 2004) and the return of biological racism (e.g. Duster 1990; Phelan, Link, and Feldman 2013) and the white supremacy (e.g. Bobo 1999). Significantly, our explicit measure of biological racism also has ecological validity, since it showed a much stronger correlation than expected $(r=.43, p<.05)$, with the results of the implicit racial bias measured across European countries by Harvard University's Project Implicit (https://www.sheffield.ac.uk/faculty/science/news/race-map-1.700171). Despite the fact that one single item was available to measure cultural racism it was possible to demonstrate its correlation with biological racism and its predictive power regarding attitudes towards immigration and immigration policies.

\section{The legitimizing role of threat perception in democratic countries}

Regarding the role of threat perception within the process involving racist beliefs, threat perceptions and discriminatory attitudes, our research is in line with the studies of Wilson, Hugenberg, and Rule (2017) and the Justified Discrimination Model (JDM) (Pereira, Vala, and Leyens 2009; Pereira, Vala, and Costa-Lopes 2010). Accordingly, threat perceptions (Blumer 1958; Bobo 1999; Stephan and Stephan 2000), clearly constitute justifying mechanisms that people who endorse racist beliefs use to legitimise their anti-normative conceptions about human nature (see also White and Crandall 2017).

The JDM was confronted with two alternative models, one setting threat perceptions as predictors of biological and cultural racism and a second one setting opposition to immigration and support for ethnicist criteria as antecedents of threat perceptions. The model representing threat perceptions as a legitimating factor of the relationship between racism and discrimination against immigrants, and consequently of the legitimation of racial based inequalities, revealed a better fit than both alternative models in all countries. This psychological and political process is specifically important in democratic societies where discrimination based on race is not allowed by law. In fact, the cross-level interactions supported this hypothesis by showing the moderating role of the Quality of Democracy.

Two explanations may be at the basis of this mechanism. Firstly, threat perceptions legitimate discrimination because they permit the racist nature underlying feelings of threat to remain unveiled (Bahns 2017; Pereira, Vala, and Costa-Lopes 2010). Moreover, the need of legitimation becomes stronger as the anti-racist norm pressure increases (Gaertner and Dovidio 2000; Pereira, Vala, and Leyens 2009), which is the case in countries that score higher in Quality of Democracy and where the egalitarian values 
are also deeply disseminated at the institutional level (Inglehart 1997; Ramos, Pereira, and Vala 2016). This second interpretation is corroborated by the results of the cross-level interactions and is extremely relevant, because it brings empirical evidence to support the importance of the inclusion of socio-structural factors in models aiming to explain individuals' social attitudes.

\section{Limitations and future studies}

As stated above, this research can help elucidate the structure and degree of expression of both biological and cultural racisms across European countries. It can also contribute to distinguishing racism from racial prejudice and to a view of racism as a social theory about the nature of humanity that sees human groups as hierarchised according to biological or cultural essences, with not all human groups having the essences that the common sense considers to be specific to humans.

However, despite the quality of the samples and the reduced rate of no answers to the central questions analysed (regarding biological racism items, the total rate of nonresponse is $5.5 \%$ varying between $0.3 \%$ in Norway and $13.5 \%$ in Latvia; regarding cultural racism, the total rate of non-response is $6.8 \%$, varying between $1.5 \%$ in Belgium and $16.2 \%$ in Austria), the number of items to measure racism was insufficient. Specifically regarding the measure of cultural racism a single item was used and at least in a prima facie it does not accentuate enough the idea of a deep hierarchy between cultures. Despite that, as hypothesised, the item positively correlates with biological racism and with ethnicist positions towards the selection of immigrants. In sum, despite the limitations already referred both items related to biological racism and to cultural racism tap a fundamental dimension of racism: the belief in the superiority of some social groups.

Limitations may also be noted regarding the fact that the answers to the racism indicators were expressed in a yes/no dichotomy scale, not allowing people to nuance their beliefs and creating data analysis limitations. The use of dichotomous items brings an additional issue for parameter estimation in structural equation modelling (e.g. Muthén and Muthén 1998-2010; Muthén and Kaplan 1985). In the current research, this issue is less accentuated because the size of the sample provides very reliable estimates for underlying latent variables (Fan, Thompson, and Wang 1999).

A single contextual variable was used (Quality of Democracy), reducing the possibility to explore the contextualisation of racial beliefs and their articulation with political and social phenomena. Some countries with extreme right-wing governments or strong right-wing parties actually score higher on racism measures, though others do not. This can either indicate a dissociation of the majority of the population from those governments and parties, or a problem of measure.

Consequently, future studies should use a more complex measure of racist beliefs and deeply explore the correlations between the racism dimensions and the contextual variables (e.g. contextual data about the vote share of far right parties, the dynamics of immigration flows and national immigration policies). Note, however, that the perspective we have explored (the interaction effects between individual and contextual levels) should be an important analytical way of exploring attitudes towards immigration. 


\section{Notes}

1. For a normative perspective on racial prejudice and racism see Pettigrew (1991), Crandall and Eshleman (2003).

2. In order to guarantee the statistical identification of the first factorial solution, the variances of the latent variables were constrained to 1.00 . The variance of cultural racism error was constrained to 0.00 and the loadings of the two indicators of biological racism were set equal to each other. The correlation between the two latent variables was freely estimated. The same strategy was used in the specification of the second factorial solution (for model identification with few items, see Kenny, Kashy, and Bolger 1998).

\section{Disclosure statement}

No potential conflict of interest was reported by the authors.

\section{ORCID}

Alice Ramos (10) http://orcid.org/0000-0001-9512-0571

Cicero Roberto Pereira (D) http://orcid.org/0000-0003-3406-3985

Jorge Vala (D) http://orcid.org/0000-0003-1265-4936

\section{References}

Arcuri, L., and S. Boca. 1999. "Posicionamentos políticos: racismo subtil e racismo flagrante em Itália" [Political positions: subtle and blatant racism in Italy.]." In Novos racismos: perspetivas comparativas, edited by Jorge Vala, 61-75. Oeiras: Celta.

Bahns, A. J. 2017. “Threat as Justification of Prejudice." Group Processes and Intergroup Relations 20 (1): 52-74. https://doi.org/10.1177/1368430215591042.

Balibar, E. 1991/2007. “Is There a Neo-Racism?" In Race and Racialization: Essential Readings, edited by C. Gupta, C. James, R. Maaka, G. Galabuzi, and C. Andersen, 83-88. Toronto: Canadian Scholars' Press.

Barker, M. 1981. Conservatives and the Ideology of Tribe. London: Junksion Books.

Blumer, H. 1958. "Race Prejudice as a Sense of Group Position.” Sociological Perspectives 1 (1): 3-7.

Bobo, L. D. 1999. "Prejudice as Group Position: Microfoundations of a Sociological Approach to Racism and Race Relations." Journal of Social Issues 55: 445-472. doi:10.1111/0022-4537.00127.

Bourhis, R. Y., L. C. Moise, S. Perrault, and S. Senecal. 1997. "Towards an Interactive Acculturation Model: A Social Psychological Approach.” International Journal of Psychology 32 (6): 369-386.

Bühlmann, M., W. Merkel, L. Müller, and B. Wessels. 2012. "The Democracy Barometer: A New Instrument to Measure the Quality of Democracy and its Potential for Comparative Research.” European Political Science 11 (4): 519-536.

Costa-Lopes, R., J. Dovidio, C. Pereira, and J. T. Jost. 2013. “Social Psychological Perspectives on the Legitimation of Social Inequality: Past, Present and Future." European Journal of Social Psychology 43 (4): 229-237.

Crandall, C. S., and A. Eshleman. 2003. "A Justification-Suppression Model of the Expression and Experience of Prejudice." Psychological Bulletin 129 (3): 414-446.

Davidov, E., B. Meuleman, J. Billiet, and P. Schmidt. 2008. "Values and Support for Immigration: A Cross-Country Comparison.” European Sociological Review 24: 583-599.

Dijksterhuis, A. 2010. "Automaticity and Unconscious." In The Handbook of Social Psychology, edited by S. T. Fiske, D. T. Gilbert, and G. Lindzey, 5th ed., Vol. 1, 228-267. New York: Willy.

Dovidio, J. F., and Samuel L. Gaertner. 1998. "On the Nature of Contemporary Prejudice: the Causes, Consequences and Challenges of Aversive Racism." In Confronting Racism: the Problem and the Response, edited by J. L. Eberhardt, and S. Fiske, 3-32. Thousand Oaks: Sage.

Duster, T. 1990. Backdoor to Eugenics. New York: Routledge. 
Fan, X., B. Thompson, and L. Wang. 1999. "Effects of Sample Size, Estimation Methods, and Model Specification on Structural Equation Modelling fit Indexes." Structural Equation Modeling: A Multidisciplinary Journal 6 (1): 56-83.

Fazio, R. H., and M. A. Olson. 2003. "Implicit Measures in Social Cognition Research: Their Meaning and use." Annual Review of Psychology 54: 297-327.

Ford, R. 2008. "Is Racial Prejudice Declining in Britain?" British Journal of Sociology 59: 609-636.

Gaertner, S. L., and J. F. Dovidio. 1986. "The Aversive Form of Racism." In Prejudice, Discrimination, and Racism, edited by Jonh F. Dovidio and Samuel L. Gaertner, 61-89. Orlando, FL: Academic Press.

Gaertner, S.L., and J.F. Dovidio. 2000. Reducing Intergroup Bias: The Common Ingroup Identity Model. Philadelphia, PA: Psychology Press.

Gaertner, S. L., and J. P. McLaughlin. 1983. "Racial Stereotypes: Associations and Ascriptions of Positive and Negative Characteristics." Social Psychology Quarterly 46: 23-30.

Gawronski, B., M. Morrison, C. E. Phills, and S. Galdi. 2017. "Temporal Stability of Implicit and Explicit Measures." Personality and Social Psychology Bulletin 43 (3): 300-312.

Green, E. G. T. 2009. "Who can Enter? A Multilevel Analysis on Public Support for Immigration Criteria Across 20 European Countries." Group Processes and Intergroup Relations 12: 41-60.

Greenwald, Anthony, Debbi E. McGhee, and Jordan L.K. Schwartz. 1998. "Measuring Individual Differences in Implicit Cognition: the Implicit Association Test." Journal of Personality and Social Psychology 74: 1464-1480.

Guimond, S., M. Dambrun, N. Michinov, and S. Duarte. 2003. "Does Social Dominance Generate Prejudice? Integrating Individual and Contextual Determinants of Intergroup Cognitions." Journal of Personality and Social Psychology 84: 697-721.

Guimond, S., R. Sablonnière, and A. Nugier. 2014. "Living in a Multicultural World: Intergroup Ideologies and the Societal Context of Intergroup Relations." European Review of Social Psychology 25 (1): 142-188.

Hafer, C., and L. Bègue. 2005. "Experimental Research on Just-world Theory: Problems, Developments, and Future Challenges.” Psychological Bulletin 131: 128-167.

Heath, A., E. Davidov, R. Ford, E. G. T. Green, A. Ramos, and P. Schmidt. 2020. "Contested Terrain: Explaining Divergent Patterns of Public Opinion Towards Immigration within Europe.” Journal of Ethnic and Migration Studies 46 (3): 475-488. doi:10.1080/1369183X.2019.1550145.

Heath, A. , S. D. Fisher, G. Rosenblatt, D. Sanders, and M. Sobolevska. 2013. The Political Integration of Ethnic Minorities in Britain. Oxford: Oxford University Press.

Huntington, S. 1996. The Clash of Civilizations and the Remaking of World Order. New York: Simon and Schuster.

Huntington, S. 2004. Who are we? The Challenges to America's National Identity. New York: Simon and Schuster.

Inglehart, R. 1997. Modernization and Post-Modernization: Cultural, Economic, and Political Change in 43 Societies. Princeton: Princeton University Press.

Jost, J. T., and O. Hunyady. 2005. “Antecedents and Consequences of System-Justifying Ideologies." Current Directions in Psychological Science 14 (5): 260-265.

Jost, J. T., and B. Major. 2001. “Emerging Perspectives on the Psychology of Legitimacy.” In The Psychology of Legitimacy: Emerging Perspective on Ideology, Justice, and Intergroup Relations, edited by J. T. Jost and B. Major, 3-30. Cambridge: Cambridge University Press.

Kenny, D. A., D. A. Kashy, and N. Bolger. 1998. "Data Analysis in Social Psychology." In The Handbook of Social Psychology. 4th ed, Vol. 1., edited by D. T. Gilbert, S.T. Fiske, and G. Lindzey, 233-265. Boston: McGraw-Hill.

Leach, C. W. 2005. "Against the Notion of a 'New Racism'." Journal of Community and Applied Social Psychology 15: 432-445.

Lévi-Strauss, C. 1952. Race et histoire. Paris: UNESCO.

Lewis, B. 2002. What Went Wrong? Western Impact and Middle Eastern Response. New York: Oxford University Press. 
McCoy, S. K., and B. Major. 2007. "Priming Meritocracy and the Psychological Justification of Inequality.” Journal of Experimental Social Psychology 43: 341-351. doi:10.1016/j.jesp.2006.04. 009.

Morales, L., J. B. Pilet, and D. Ruedin. 2015. "The gap Between Public Preferences and Policies on Immigration: A Comparative Examination of the Effect of Politicisation on Policy Congruence." Journal of Ethnic and Migration Studies 41(9): 1495-1516. http://doi.org/10.1080/1369183X. 2015.1021598 [Article included in the special issue 'The Public and the Politics of Immigration Control', edited by Chris Gilligan.

Muthén, B., and D. Kaplan. 1985. "A Comparison of Some Methodologies for the Factor Analysis of non-Normal Likert Variables.” British Journal of Mathematical and Statistical Psychology 38: 171-189.

Muthén, L. K., and B. O. Muthén. 1998-2010. Mplus User's Guide. 6th ed. Los Angeles, CA: Muthén \& Muthén.

Nosek, B. A., A. Greenwald, and M. R. Banaji. 2005. "Understanding and Using the Implicit Association Test: II. Method Variables and Construct Validity." Personality and Social Psychology Bulletin 31 (2): 166-180. doi:10.1177/0146167204271418.

Pehrson, S., and E. G.T. Green. 2010. "Who we are and who can Join us: National Identity Content and Entry Criteria for new Immigrants.” Journal of Social Issues 66 (4): 695-716. doi:10.1111/j. 1540-4560.2010.01671.x.

Pereira, C., and J. Vala. 2012. Biological and Cultural Racism: Operationalization and Validation of a Scale. Unpublished manuscript, Instituto de Ciências Sociais, Lisboa.

Pereira, C., J. Vala, and R. Costa-Lopes. 2010. "From Prejudice to Discrimination: The Legitimizing Role of Perceived Threat Indiscrimination Against Immigrants." European Journal of Social Psychology 40: 1231-1250. doi:10.1002/ejsp.718.

Pereira, C., J. Vala, and J.-P. Leyens. 2009. "From Infra-Humanization to Discrimination: The Mediation of Symbolic Threat Needs Egalitarian Norms." Journal of Experimental Social Psychology 45: 336-344. doi:10.1016/j.jesp.2008.10.010.

Pérez, J. 1996. "Nuevas Formas de Racismo.” In Del Prejuicio al Racismo: Perspectivas Psicosociales, edited by J. Morales and S. Yubero, 79-102. Cuenca: Cuenca Editiones de la Universidad Castillala-Mancha.

Pettigrew, T. F. 1991. "Normative Theory in Inter-Group Relations: Explaining Both Harmony and Conflict." Psychology and Developing Societies 3: 3-16.

Pettigrew, T. F., and R. W. Meertens. 1995. "Subtle and Blatant Prejudice in Western Europe." European Journal of Social Psychology 25 (1): 57-75. doi:10.1002/ejsp.2420250106.

Phelan, Jo C., Bruce G. Link, and Feldman, Naumi M. 2013. “The Genomic Revolution and Beliefs About Essential Racial Differences: A Backdoor to Eugenics?” American Sociological Review 78 (2): 167-191. https://doi.org/10.1177/0003122413476034

Quillian, L. 2006. "New Approaches to Understanding Racial Prejudice and Discrimination." Annual Review of Sociology 32 (1): 299-328.

Ramos, A., C. Pereira, and J. Vala. 2016. "Economic Crisis, Human Values and Attitudes Towards Immigration.” In Values, Economic Crisis and Democracy, edited by Malina Voicu, Ingvill C. Mochmann, and Hermann Dülmer, 104-137. Abingdon: Routledge.

Said, E. 1994. Orientalism. 2nd ed. New York: Vintage.

Sears, D., and J. B. McConahay. 1973. The Politics of Violence: The New Urban Blacks and the Watts Riots. Boston: Houghton-Mifflin.

Sidanius, J., and F. Pratto. 1999. Social Dominance: An Inter-Group Theory of Social Hierarchy and Oppression. New York: Cambridge University Press.

Stephan, W. G., and C. W. Stephan. 2000. "An Integrated Threat Theory of Prejudice.” In Reducing Prejudice and Discrimination, edited by Stuart Oskamp, 23-45. Mahwah, NJ: Erlbaum.

Taguieff, P.-A. 1984. "Les présuppositions définitionnelles de l’indéfinissable: le Racim.” Mots 8: 71107.

Tyler, T. R. 2006. "Psychological Perspectives on Legitimacy and Legitimation.” Annual Review of Psychology 57: 375-400. 
Vala, J. 2013. “Racisms: Social Representations, Racial Prejudice and Normative Pressures.” Papers on Social Representations 22: 6.1-6.29.

Vala, J., D. Lopes, and R. Brito. 1999. As Expressões dos Racismos em Portugal. Lisboa: Imprensa de Ciências Sociais. http://repositorio.ul.pt/bitstream/10451/22539/1/ICS_JVala_Racismos_LAN. pdf.

Vala, J., D. Lopes, and M. Lima. 2008. "Black Immigrants in Portugal: Luso-Tropicalism and Prejudice.” Journal of Social Issues 64 (2): 287-302.

Vala, J., C. R. Pereira, M. Lima, and J.-P. Leyens. 2012. “Intergroup Time Bias and Racialized Social Relations." Personality and Social Psychology Bulletin 38 (4): 491-504.

Walker, I. 2004. “The Changing Nature of Racism: From old to new?" In Understanding the Psychology of Prejudice and Racism, edited by M. Augoustinos and K. J. Reynolds, 24-42. London: Sage. doi:10.4135/9781446218877.n2.

White, M. H. II, and C. S. Crandall. 2017. "Freedom of Racist Speech: Ego and Expressive Threats." Journal of Personality and Social Psychology 113 (3): 413-429. doi:10.1037/pspi0000095.

Wilson, J. P., K. Hugenberg, and N. O. Rule. 2017. "Racial Bias in Judgments of Physical Size and Formidability: From Size to Threat." Journal of Personality and Social Psychology 113 (1): 59-80. doi:10.1037/pspi0000092.

Zick, A., T. Pettigrew, and U. Wagner. 2008. "Ethnic Prejudice and Discrimination in Europe." Journal of Social Issues 64: 233-251. 